\title{
The "Pink Pattern" Visualized in Magnifying Endoscopy with Narrow-Band Imaging is a New Feature of Early Gastric Differentiated Cancer--A Bridge Between Endoscopic Image and Histopathological Change
}

\author{
Shengsen Chen \\ Zhejiang Cancer Hospital \\ Jiangping Yu \\ Zhejiang Cancer Hospital \\ Rongwei Ruan \\ Zhejiang Cancer Hospital \\ Yali Tao \\ Zhejiang Cancer Hospital \\ Zhao Cui \\ Zhejiang Cancer Hospital \\ Yandong Li \\ Zhejiang Cancer Hospital \\ Cheng Shen \\ Hithink information network \\ Jiayan Jin \\ Hithink information network \\ Ming Chen \\ Hithink Information Network \\ Chaohui Jin \\ Hithink Information Network \\ Shi Wang ( $\sim$ wangshi@zjcc.org.cn ) \\ Zhejiang Cancer Hospital
}

\section{Research}

Keywords: Pink pattern, Vessel-plus-surface classification system, Early gastric cancer, Magnifying endoscopy, Histopathological change

Posted Date: June 15th, 2021

DOI: https://doi.org/10.21203/rs.3.rs-596301/v1

License: @ (i) This work is licensed under a Creative Commons Attribution 4.0 International License. Read Full License 


\section{Abstract \\ Background}

A pink color change found occasionally by us under the magnifying endoscopy with narrow-band imaging (ME-NBI) may be a special feature of early gastric cancer (EGC), and it was named as "pink pattern". The purposes of this study were to reveal the relationship between the "pink pattern" and the cytopathological changes of gastric cancer cells, and explore whether the pink pattern was useful for the diagnosis of EGC.

\section{Methods}

The color features of ME-NBI images and pathological images on gastric cancerous mucosal surface were extracted and quantized, and then the cosine similarity was calculated to evaluate the correlation between the pink pattern and the nucleus-to-plasm ratio of cancerous epithelial cells. Two diagnostic tests were performed by 12 endoscopists using stored ME-NBI images of 185 gastric lesions to investigate the diagnostic efficiency of "pink pattern" for EGC. The diagnostic values such as area under curve (AUC), accuracy, sensitivity, specificity, positive predictive value (PPV) and negative predictive value (NPV) between test 1 and test 2 were compared.

\section{Results}

The cosine similarity in 20 lesions between the color values of ME-NBI images and pathological images was at least 0.744. The median AUC, accuracy, sensitivity, specificity, PPV and NPV of test 2 were significantly improved compared with that of test 1 in all endoscopists, junior and experienced groups.

\section{Conclusions}

The "pink pattern" visualized in ME-NBI images is highly correlated with the nucleus-to-plasma ratio change of gastric epithelial cells, and it can be considered as a useful marker for the diagnosis of the differentiated EGC.

\section{Background}

As one of the most common cancer worldwide, gastric cancer globally ranks fifth and fourth in morbidity and mortality respectively. In 2020, the number of new cases exceeds 1 million and the estimated death is 769,000 (equivalent to every 13 deaths has 1 case died of gastric cancer worldwide) [1]. Early detection of gastric cancer is essential to obtain a good prognosis. The magnifying endoscopy with narrow-band imaging (ME-NBI) is a new powerful optical imaging technique that has significantly improved the endoscopic diagnosis by applying the narrow band filters [2]. The microvascular architecture and microsurface structure of the gastrointestinal tract can be clearly visualized by ME-NBI [3]. So the ME-NBI has been widely used for the diagnosis of early gastric cancer (EGC) $[4,5]$.

Yao et al. analyzed gastric cancer images under ME-NBI and proposed a gastric cancer diagnosis system, named "vessel-plus-surface (VS) classification system" [4, 6, 7]. This system is particularly capable of distinguishing superficial type 0-II differentiated gastric cancer, while it is difficult to distinguish cancers in the pale lesions (mostly undifferentiated cancer and signet ring cell carcinoma) [8, 9]. When applying the VS classification system for EGC diagnosis, the most important step is to determine whether there is $\mathrm{DL}$ in the suspicious lesion. $\mathrm{DL}$ is defined as a 
boundary line between the cancerous area and the non-cancerous area. Obvious irregular MV pattern (IMVP) and/or irregular MS pattern (IMSP) can be seen within DL[4, 8, 9]. However, in the actual endoscopic examination, the DL of differentiated EGC is sometimes indeterminate, or the DL can be visible but the IMVP and/or IMSP are indeterminate [10]. At this time, it is difficult to accurately discern the cancerous lesion through the VS classification system under ME-NBI. Therefore, it is imperative to look for a new endoscopic feature of differentiated gastric cancer to help endoscopists improve their confidence in endoscopic diagnosis for EGC when they difficult to determine DL or IMVP/IMSP according to the VS classification system.

When in the observation of EGC, gastric mucosal surface color is usually interfered by the surface microvessel, so the color change of superficial mucosal epithelium is easily ignored. We occasionally discovered that a pink color change on superficial mucosal epithelium was visualized in the suspicious gastric malignant lesions under ME-NBI when the DL of these lesions was either indeterminate (Fig. 1) or clear (Figure S1). Then the lesions that showed pink color change with DL indeterminate or present were confirmed as gastric cancer by histological examination (Fig. 2 and Fig. 2S). Finally, we named the pink color change of gastric cancer lesion under ME-NBI as "pink pattern". Interestingly, based on the further observation of the histologpathological slices, we found that the nucleus-toplasma ratio of the epithelial cells in the cancerous lesions were obviously increased compared with the non cancerous lesions (Fig. 2 and Figure S2). Therefore, for the gastric cancer lesion, we hypothesized that this pink pattern in ME-NBI image may be highly correlated with the nucleus-to-plasma ratio change of gastric epithelial cells in histologpathological image.

In this study, we tried to verify our hypothesis mentioned above by using computer image processing technique and explored the pink pattern observed under ME-NBI whether is greatly useful for EGC diagnosis by taking diagnostic test among 12 endoscopists, then aimed to propose a new efficient strategy for EGC diagnosis by using ME-NBI.

\section{Methods}

\section{Endoscopy system and endoscopy procedures}

All images were taken by electronic endoscopy system with NBI (high-resolution optical magnifying endoscopes, GIFH290Z and GIF-H260Z; Olympus). First, endoscopic examinations were performed by endoscopists using white light imaging. After finding suspicious lesions, the magnified observation was taken by fixing the NBI mode. A soft black hood was mounted on the tip of the scope, enabling the endoscopist to consistently fix the distance between the tip of the scope and the target lesion at $2 \mathrm{~mm}$ approximately, then the endoscopic images with maximal magnification were obtained. High-quality NBI images of the lesions were selected for subsequent diagnostic tests. All lesions had not been taken biopsy before the ME-NBI examination.

\section{Histopathological examination}

The endoscopic submucosal dissection (ESD) specimens or biopsy specimens were fixed with $20 \%$ formalin for 24 hours, then the fixed tissues were embedded in paraffin and sliced at $2 \mathrm{~mm}$ intervals, keeping the thickness of the slices at $5 \mu \mathrm{m}$. Finally the slices were stained with hematoxylin and eosin (HE) and histopathologically examined under light microscope. Histopathological diagnoses were made with reference to the revised Vienna classification (C1 to C5) [11].

\section{Endoscopic image processing}


The steps of endoscopic image processing are summarized in Fig. 3. We used the fastGlobalSmootherFilter algorithm from the Opencv library to process the input image (Image I) to obtain the Image L, and then performd Gamma correction on Image $L$, and adjusted the light balance and brightness to obtain the Image $R$ according to the following formula: Image $R=$ Image I/Image $L^{\lambda}(\lambda=0.75)$. In order to make the texture color difference between the crypt epithelium and the background more obvious, we called the cvtColor function of the Opencv library to convert the BGR (B, blue; $G$, green; R, red) image (ImgBGR) to the grayscale image (ImgGray), and then used the fastGlobalSmootherFilter function of the Opencv library to calculate the smoothed filter image (ImgGSF), and subsequently obtained the texture enhancement image (ImgEnhance) by using the following formula: ImgEnhance= ImgGray - ImgGSF. Finally, we called the Otsu thresholding algorithm of Opencv library to extract the Mask from the ImgEnhance.

Mask0 after dilation of Mask was used as a possible foreground. Then Mask1 after erosion of Mask was taken as a definite foreground. After that, Mask0 and Mask1 were overlayed to create Mask2, and the pixel value of Mask0 and Mask 1 was set as 3 and 1 respectively. Finally, we called the Grabcut algorithm in the Opencv library to accurately cut the Mask2 and obtained the Mask3. The gray world algorithm was used to correct the color of the endoscopic image, and then the endoscopic image was filtered to remove the image noise by calling GaussianBlur function of Opencv library. A line was drawn artificially in the endoscope image, and next the part of superficial mucosal epithelium on the line was extracted from the Mask3. The points with the highest saturation value on each part of superficial mucosal epithelium were extracted and their saturation values were listed. It is worth noting that the range of saturation values is $0 \sim 255$. The greater the saturation value, the closer the color of superficial mucosal epithelium is to red, the smaller the saturation value is, the closer the color of superficial mucosal epithelium is to white. The whole steps of endoscopic image processing were performed by python.

\section{Pathological image processing}

The detailed steps of pathological image processing are shown in Fig. 4. We called the GaussianBlur function in the Opencv library to remove the noise of pathological image. The pathological image was converted from RGB image to grayscale image by calling the cvtColor function in the Opencv library. We called the threshold function in the Opencv library and performd the Otsu thresholding algorithm on the pathological grayscale image to obtain the black-and-white image. The edge detection on the pathological black-and-white image was performed to obtain the edge contour by using the findContours function in the Opencv library. Then we cut the contour into upper and lower parts, calculated the average gray value of the two parts, and took the part with lower gray value as the edge zone for study.

The edge zone with lower gray value was intercepted at 20 pixels equidistantly in the horizontal direction, and the points with the lowest gray value in each intercepted block were extracted as the sampling point. As is well known, the gray value range is $0 \sim 255$ in digital image, the black pixel value is 0 and white is 255 , the darker the pixel color, the smaller the gray value. So in the HE-stained pathological image, the smaller the gray value is, the closer the color of sampling point is to purple. In order to match the color curve trend of the endoscopic image, the HE-stained pathological image here used 255 minus gray value as the color value of sampling point. Finally, the gray values of each sampling point in edge zone of HE-stained pathological image were obtained and listed. All steps of pathological image processing were performed by python.

\section{Similarity evaluation}

The list length of the color values from feature points between the pathological image and endoscopic image is different due to the different size between the pathological image and endoscopic image. In order to calculate the 
cosine similarity between the saturation value of the endoscopic image and the gray value of the pathological image, the gray values list of pathological image was averagely sampled (Fig. 5a) to make it consistent with the length of the saturation values list of the endoscopic image(Fig. 5b).

$$
\left[\begin{array}{lllllllllllllll}
x_{1} & x_{2} & x_{3} & x_{4} & x_{5} & x_{6} & x_{7} & x_{8} & x_{9} & x_{10} & \Lambda & x_{n-3} & x_{n-2} & x_{n-1} & x_{n}
\end{array}\right]
$$

The saturation values list of the endoscopic image in the line:

$$
\left[\begin{array}{lllllllllllllll}
y_{1} & y_{2} & y_{3} & y_{4} & y_{5} & y_{6} & y_{7} & y_{8} & y_{9} & y_{10} & \Lambda & y_{n-3} & y_{n-2} & y_{n-1} & y_{n}
\end{array}\right]
$$

The gray values list of pathological image in edge zone:

$$
\text { Similarity }=\operatorname{Cos}(\theta)=\frac{\mathrm{x} \cdot \mathrm{y}}{\|\mathrm{x}\| \times\|\mathrm{y}\|}=\frac{\sum_{\mathrm{i}=1}^{\mathrm{n}}\left(\mathrm{x}_{\mathrm{i}} \times \mathrm{y}_{\mathrm{i}}\right)}{\sqrt{\sum_{\mathrm{i}=1}^{\mathrm{n}}\left(\mathrm{x}_{\mathrm{i}}\right)^{2}} \times \sqrt{\sum_{\mathrm{i}=1}^{\mathrm{n}}\left(\mathrm{y}_{\mathrm{i}}\right)^{2}}}
$$

Cosine similarity is a metric used to determine how similar the vectors are irrespective of their size. Mathematically, it calculates the cosine of the angle between two vectors projected in a multi-dimensional space[12, 13]. The calculation formula is as follows:

When the two vectors have the same direction, the value of cosine similarity is 1 ; while the directions of the two vectors are opposite, the value of cosine similarity is -1 ; when the angle between the two vectors is $90^{\circ}$, the value of cosine similarity is $0[12,13]$. The cosine similarity value ranges from -1 to 1 , the closer the value is to 1 , the closer the directions of the two lists above are, that is, the more similar the two lists are (Fig. $5 \mathrm{c}$ ). The processes of cosine similarity calculation above were also performed by python.

\section{Participating endoscopists}

We recruited 12 endoscopists from our department as participants who had used VS classification system for EGC diagnosis before. Among them, 6 were assigned to experienced group who had performed more than 10000 conventional endoscopy examinations, and another 6 were assigned to junior group who had performed less than 10000 but also still more than 2000 conventional endoscopy examinations. Participant demographics are presented in Table 1. In order to minimize diagnostic variation between these endoscopists, they were taken training about using pink pattern to diagnose gastric cancer with ME-NBI. 
Table 1

Characteristics of the 12 participants

\begin{tabular}{|ll|}
\hline Characteristic & Value \\
\hline Sex, $\mathrm{n}$ & \\
\hline Male & 7 \\
\hline Female & 5 \\
\hline Mean age, years(SD) & $34.3(4.7)$ \\
\hline No. of endoscopies conducted, $\mathrm{n}$ & \\
\hline$<10,000$ (junior) & 6 \\
\hline$\geq 10,000$ (experienced) & 6 \\
\hline No. of cases for differential diagnosis by using ME-NBI, $\mathrm{n}$ & \\
\hline$<100$ & 4 \\
\hline$\geq 100$ & 8 \\
\hline
\end{tabular}

SD, Standard deviation; M-NBI, magnifying endoscopy with narrow-band imaging

\section{Diagnostic tests}

ME-NBI images of 185 gastric lesions were selected for diagnostic tests (95 cancerous and 90 non-cancerous). The characteristics of the 185 lesions are shown in Table 2. All of the images from 185 lesions were taken by an expert endoscopist at Zhejiang Cancer Hospital. Two diagnostic tests were taken in this study and used the same 185 gastric lesions. For test 1, each participant evaluated the M-NBI images according to the VS classification system; for test 2, the images of 185 gastric lesions were evaluated by these participants based on VS classification system plus the "pink pattern". The 12 endoscopists all were isolated and did the two tests alone, which avoid other participants' interference. The detailed flow of diagnostic test is shown in Fig. 6. 
Table 2

Characteristics of the 185 gastric lesions used for diagnostic tests

\begin{tabular}{|c|c|c|}
\hline Characteristics & $\begin{array}{l}\text { Cancer } \\
(n=95)\end{array}$ & $\begin{array}{l}\text { Noncancer } \\
(\mathrm{n}=90)\end{array}$ \\
\hline \multicolumn{3}{|l|}{ Histologic type, n(\%) } \\
\hline Well-differentiated adenocarcinoma & $69(72.6)$ & NA \\
\hline Moderately differentiated adenocarcinoma & $26(27.4)$ & NA \\
\hline Low-grade adenoma & NA & $7(7.8)$ \\
\hline Chronic gastritis & NA & $83(92.2)$ \\
\hline \multicolumn{3}{|l|}{ Macroscopic appearance, n(\%) } \\
\hline Elevated lesion & $29(30.5)$ & 17(18.9) \\
\hline Flat lesion & 11(11.6) & $24(26.7)$ \\
\hline Depressed lesion & $55(57.9)$ & $49(51.6)$ \\
\hline \multicolumn{3}{|l|}{ Mean size, $\mathrm{n}(\%)$} \\
\hline$\geq 1 \mathrm{~cm}$ & $67(70.5)$ & $19(21.1)$ \\
\hline$<1 \mathrm{~cm}$ & $28(29.5)$ & 71(78.9) \\
\hline \multicolumn{3}{|l|}{ Depth of invasion, $\mathrm{n}(\%)$} \\
\hline Mucosa & $83(87.4)$ & $90(100)$ \\
\hline Submucosa & $12(12.6)$ & 0 \\
\hline \multicolumn{3}{|l|}{ Location, n(\%) } \\
\hline Lower third & $33(34.7)$ & $39(43.3)$ \\
\hline Middle third & $39(41.1)$ & $35(38.9)$ \\
\hline Upper third & $23(24.2)$ & $16(17.8)$ \\
\hline
\end{tabular}

NA, Not applicable.

\section{Statistical analysis}

The diagnostic performance of test 1 and test 2 was evaluated by calculating the area under the curve (AUC), accuracy, sensitivity, specificity, PPV and NPV. The comparison of the changes in these diagnostic values between tests 1 and 2 was calculated using Mann-Whitney test. The agreement of 12 endoscopists was evaluated by calculating Fleiss' kappa value (slight agreement: 0.01 to 0.20 ; fair agreement: 0.21 to 0.40 ; moderate agreement: 0.41 to 0.60 ; substantial agreement: 0.61 to 0.80 , and almost perfect agreement: 0.81 to 1.00 ) [14]. Each test was 2sided, and $\mathrm{P}<0.05$ was considered statistically significant. All analyses were conducted using $R$, version 4.0.3 ( $R$ Project for Statistical Computing, Vienna, Austria) and GraphPad rism 8 (GraphPad Software, Inc, San Diego, Calif).

\section{Results}




\section{The cosine similarity between the endoscopic image and pathological image}

We used the computer image processing technology described above in the method section to extract the color features of selected high quality endoscopic images and pathological images of 20 representative lesions, and then calculated the cosine similarity between the endoscopic images and pathological images in the same lesions. The results showed that the cosine similarity between the color values of ME-NBI images and HE-stained pathological images in 20 lesions all were greater than 0.70 (median, 0.894; minimum 0.744; maximum, 0.981), indicating that the pink pattern visualized in the ME-NBI images was highly correlated with the color changes of the HE-stained pathological image on these 20 lesions. The detailed cosine similarity values and other information were summarized in Table 3 
Table 3

The detailed information of lesions selected for image color extraction to calculate cosine similarity

\begin{tabular}{|c|c|c|c|c|c|c|c|c|}
\hline $\begin{array}{l}\text { Lesion } \\
\text { No. }\end{array}$ & Sex & Age(years) & Location & $\begin{array}{l}\text { Lesion } \\
\text { size }(\mathrm{cm})\end{array}$ & $\begin{array}{l}\text { Invasion } \\
\text { depth }\end{array}$ & $\begin{array}{l}\text { Histological } \\
\text { type }\end{array}$ & $\begin{array}{l}\text { Paris } \\
\text { classification }\end{array}$ & ConSim \\
\hline 1 & Female & 53 & $\begin{array}{l}\text { Gastric } \\
\text { antrum }\end{array}$ & 1.0 & Mucosa & $\begin{array}{l}\text { Well } \\
\text { differentiated }\end{array}$ & Ilb & 0.939 \\
\hline 2 & Female & 53 & $\begin{array}{l}\text { Gastric } \\
\text { angle }\end{array}$ & 2.5 & Mucosa & $\begin{array}{l}\text { Well } \\
\text { differentiated }\end{array}$ & Ila & 0.833 \\
\hline 3 & Male & 66 & $\begin{array}{l}\text { Gastric } \\
\text { angle }\end{array}$ & 1.0 & Mucosa & $\begin{array}{l}\text { Well } \\
\text { differentiated }\end{array}$ & Ila + Ilc & 0.936 \\
\hline 4 & Male & 82 & $\begin{array}{l}\text { Gastric } \\
\text { antrum }\end{array}$ & 1.0 & Mucosa & $\begin{array}{l}\text { Moderately } \\
\text { to well } \\
\text { differentiated }\end{array}$ & Ila & 0.892 \\
\hline 5 & Female & 58 & $\begin{array}{l}\text { Gastric } \\
\text { angle }\end{array}$ & 1.0 & Mucosa & $\begin{array}{l}\text { Moderately } \\
\text { to well } \\
\text { differentiated }\end{array}$ & Ilc & 0.882 \\
\hline 6 & Male & 66 & Cardia & 2.5 & Mucosa & $\begin{array}{l}\text { Well } \\
\text { differentiated }\end{array}$ & $\mathrm{Ilb}$ & 0.948 \\
\hline 7 & Male & 64 & $\begin{array}{l}\text { Gastric } \\
\text { antrum }\end{array}$ & 2.4 & Mucosa & $\begin{array}{l}\text { Moderately } \\
\text { differentiated }\end{array}$ & Ila + Ilc & 0.84 \\
\hline 8 & Male & 64 & $\begin{array}{l}\text { Gastric } \\
\text { antrum }\end{array}$ & 1.2 & Mucosa & $\begin{array}{l}\text { Moderately } \\
\text { differentiated }\end{array}$ & $I I c+I I b$ & 0.856 \\
\hline 9 & Male & 64 & $\begin{array}{l}\text { Junction } \\
\text { of } \\
\text { gastric } \\
\text { antrum } \\
\text { and } \\
\text { body }\end{array}$ & 2.4 & Mucosa & $\begin{array}{l}\text { Well } \\
\text { differentiated }\end{array}$ & Ilb & 0.936 \\
\hline 10 & Male & 45 & $\begin{array}{l}\text { Gastric } \\
\text { antrum }\end{array}$ & 4.0 & Mucosa & $\begin{array}{l}\text { Well } \\
\text { differentiated }\end{array}$ & Ila + Ilc & 0.857 \\
\hline 11 & Male & 66 & $\begin{array}{l}\text { Gastric } \\
\text { angle }\end{array}$ & 1.5 & Mucosa & $\begin{array}{l}\text { Moderately } \\
\text { differentiated }\end{array}$ & Ilc & 0.895 \\
\hline 12 & Male & 62 & $\begin{array}{l}\text { Gastric } \\
\text { antrum }\end{array}$ & 1.2 & Mucosa & $\begin{array}{l}\text { Poorly to } \\
\text { moderately } \\
\text { differentiated }\end{array}$ & IIC & 0.831 \\
\hline 13 & Male & 58 & $\begin{array}{l}\text { Gastric } \\
\text { body }\end{array}$ & 1.2 & Mucosa & $\begin{array}{l}\text { Well } \\
\text { differentiated }\end{array}$ & Ila + IIc & 0.907 \\
\hline 14 & Male & 58 & $\begin{array}{l}\text { Gastric } \\
\text { body }\end{array}$ & 1.0 & Mucosa & $\begin{array}{l}\text { Well } \\
\text { differentiated }\end{array}$ & Ilb & 0.892 \\
\hline 15 & Female & 63 & $\begin{array}{l}\text { Gastric } \\
\text { antrum }\end{array}$ & 1.0 & Mucosa & $\begin{array}{l}\text { Well } \\
\text { differentiated }\end{array}$ & Ilb & 0.833 \\
\hline 16 & Male & 77 & $\begin{array}{l}\text { Lower } \\
\text { edge of } \\
\text { cardia }\end{array}$ & 2.0 & Mucosa & $\begin{array}{l}\text { Poorly to } \\
\text { moderately } \\
\text { differentiated }\end{array}$ & Ilb & 0.896 \\
\hline 17 & Female & 56 & Cardia & 1.0 & Mucosa & $\begin{array}{l}\text { Moderately } \\
\text { to well } \\
\text { differentiated }\end{array}$ & Ilc & 0.96 \\
\hline
\end{tabular}




\begin{tabular}{|lllllllll|}
\hline $\begin{array}{l}\text { Lesion } \\
\text { No. }\end{array}$ & Sex & Age(years) & Location & $\begin{array}{l}\text { Lesion } \\
\text { size(cm) }\end{array}$ & $\begin{array}{l}\text { Invasion } \\
\text { depth }\end{array}$ & $\begin{array}{l}\text { Histological } \\
\text { type }\end{array}$ & $\begin{array}{l}\text { Paris } \\
\text { classification }\end{array}$ & ConSim \\
\hline 18 & Male & 73 & Cardia & 1.0 & Mucosa & $\begin{array}{l}\text { Moderately } \\
\text { to well } \\
\text { differentiated }\end{array}$ & Ila & $\mathbf{0 . 9 3}$ \\
\hline 19 & Male & 58 & $\begin{array}{l}\text { Gastric } \\
\text { antrum }\end{array}$ & 2.0 & Mucosa & $\begin{array}{l}\text { Well } \\
\text { differentiated }\end{array}$ & Ila & $\mathbf{0 . 7 4 4}$ \\
\hline 20 & Female & 61 & $\begin{array}{l}\text { Lower } \\
\text { edge of } \\
\text { cardia }\end{array}$ & 2.0 & Mucosa & $\begin{array}{l}\text { Poorly to } \\
\text { moderately } \\
\text { differentiated }\end{array}$ & Ilc & $\mathbf{0 . 9 8 1}$ \\
\hline
\end{tabular}

ConSim: Cosine similarity.

\section{Diagnostic performance comparison between tests 1 and 2}

For test 1, endoscopists evaluated the M-NBI images according to the VS classification system; while in test 2, all participants made the endoscopic diagnosis based on VS classification system plus the "pink pattern". The detailed diagnostic performance of the test 1 and test 2 are shown in Table 3 . Test 2 did by all endoscopists achieved significantly higher AUC, accuracy, sensitivity, specificity, PPV and NPV than that of test 1(Fig. 7a). When the comparison of the two tests was made in junior and experienced groups, the test 2 again had statistically higher accuracy, sensitivity, specificity, PPV and NPV (Fig. 7b and 7c). Additionally, in test 1, these five diagnostic values above from the experienced group was significantly higher than that of the junior group. However, in test 2 , experienced group significantly carried out higher AUC, accuracy, sensitivity, PPV and NPV than that of junior group, but the specificity showed no statistical difference between experienced and junior groups and tended to be higher in experienced group (Figure S3).

\section{Interobserver agreement}

Table 4 shows interobserver agreement of 12 participants in tests 1 and test 2 . Fleiss' kappa values of all endoscopists, junior and experienced groups were increased in test 2(from 0.51 to $0.65,0.47$ to 0.58 and 0.60 to 0.76 , respectively). According to the analysis, although the experience of endoscopy conducting is different in these participants, a moderate agreement was demonstrated in all endoscopists, junior and experienced groups after taking test 1 , and the interpretations of all endoscopists and experienced groups were improved into substantial agreement in test 2 . 
Table 4

Diagnostic performance comparison between tests 1 and 2 for all gastric lesions

\begin{tabular}{|c|c|c|c|c|c|c|}
\hline \multirow{2}{*}{$\begin{array}{l}\text { Diagnostic } \\
\text { parameter }\end{array}$} & \multicolumn{2}{|c|}{ All endoscopists $(n=12)$} & \multicolumn{2}{|c|}{ Junior(n = 6) } & \multicolumn{2}{|c|}{ Experienced $(n=6)$} \\
\hline & Test 1 & Test 2 & Test 1 & Test 2 & Test 1 & Test 2 \\
\hline $\begin{array}{l}\text { AUC(\%), } \\
\text { median(range) }\end{array}$ & $\begin{array}{l}79.0(68.5- \\
85.6)\end{array}$ & $\begin{array}{l}87.3(79.3- \\
92.6)\end{array}$ & $\begin{array}{l}72.8(68.5- \\
75.0)\end{array}$ & $\begin{array}{l}80.2(79.3- \\
86.2)\end{array}$ & $\begin{array}{l}84.8(83.0- \\
85.6)\end{array}$ & $\begin{array}{l}90.7(88.3- \\
92.6)\end{array}$ \\
\hline $\begin{array}{l}\text { Accuracy(\%), } \\
\text { median(range) }\end{array}$ & $\begin{array}{l}78.7(68.1- \\
85.4)\end{array}$ & $\begin{array}{l}87.0(79.0- \\
92.4)\end{array}$ & $\begin{array}{l}72.5(68.1- \\
74.6)\end{array}$ & $\begin{array}{l}90.6(88.1- \\
92.4)\end{array}$ & $\begin{array}{l}84.6(82.7- \\
85.4)\end{array}$ & $\begin{array}{l}90.6(88.1- \\
92.4)\end{array}$ \\
\hline $\begin{array}{l}\text { Sensitivity(\%), } \\
\text { median(range) }\end{array}$ & $\begin{array}{l}\text { 67.4(54.7- } \\
81.1)\end{array}$ & $\begin{array}{l}78.4(64.2- \\
88.4)\end{array}$ & $\begin{array}{l}57.4(54.7- \\
62.1)\end{array}$ & $\begin{array}{l}67.4(64.2- \\
76.8)\end{array}$ & $\begin{array}{l}77.9(82.6- \\
81.1)\end{array}$ & $\begin{array}{l}85.8(80.0- \\
88.4)\end{array}$ \\
\hline $\begin{array}{l}\text { Specificity(\%), } \\
\text { median(range) }\end{array}$ & $\begin{array}{l}90.0(82.2- \\
94.4)\end{array}$ & $\begin{array}{l}95.0(91.1- \\
98.9)\end{array}$ & $\begin{array}{l}86.2(82.2- \\
91.1)\end{array}$ & $\begin{array}{l}93.9(91.1- \\
96.7)\end{array}$ & $\begin{array}{l}91.7(88.9- \\
94.4)\end{array}$ & $\begin{array}{l}96.2(93.3- \\
98.9)\end{array}$ \\
\hline $\begin{array}{l}\text { PPV(\%), } \\
\text { median(range) }\end{array}$ & $\begin{array}{l}87.7(76.5- \\
93.6)\end{array}$ & $\begin{array}{l}94.5(89.0- \\
98.7)\end{array}$ & $\begin{array}{l}81.5(76.5- \\
87.1)\end{array}$ & $\begin{array}{l}92.2(89- \\
95.3)\end{array}$ & $\begin{array}{l}90.8(88.2- \\
93.6)\end{array}$ & $\begin{array}{l}95.8(93.3- \\
98.7)\end{array}$ \\
\hline $\begin{array}{l}\text { NPV(\%), } \\
\text { median(range) }\end{array}$ & $\begin{array}{l}72.25(63.2- \\
81.8)\end{array}$ & $\begin{array}{l}80.9(71.9- \\
88.4)\end{array}$ & $\begin{array}{l}66.4(63.2- \\
68.1)\end{array}$ & $\begin{array}{l}\text { 72.7(71.9- } \\
79.6)\end{array}$ & $\begin{array}{l}\text { 79.7(76.4- } \\
81.8)\end{array}$ & $\begin{array}{l}86.4(82.1- \\
88.4)\end{array}$ \\
\hline
\end{tabular}

AUC, area under curve; PPV, positive predictive value; NPV, negative predictive value.

\section{Discussion}

In the diagnosis of gastric mucosal lesions by endoscopy, it is important to distinguish between tumors and nontumors. Pathological evaluation by biopsy is the gold standard for the diagnosis of gastric epithelial tumors. In recent years, with the increase in the incidence of cardiovascular and cerebrovascular diseases, the number of patients taking antithrombotic drugs has been growing $[10,14]$. Moreover, most inexperienced endoscopists usually take multiple biopsies during the operation, which will aggravate the tissue damage. Therefore, it's imperative to find a method to keep the number of biopsies during endoscopy as low as possible. Studies have confirmed that ME-NBI can significantly improve the diagnostic performance for gastric mucosal lesions and reduce the number of biopsies when diagnosing tumors [10]. At present, the VS classification system is commonly used to diagnose gastric cancer under the ME-NBI. For applying the VS classification system to determine whether the suspected lesion is cancerous, the DL needs to be clarified first [8]. However, not all suspected lesions have clear DL and/or IMVP/IMSP [5, 10]. When the DL and/or IMVP/IMSP are indeterminate, the accuracy of the VS classification system in diagnosing gastric cancer will decrease. Under this circumstance, the diagnosis mainly depends on the lesion biopsy. So how can we maintain a high accuracy rate of diagnosing gastric cancer without increasing the number of biopsy when the DL and/or IMVP/IMSP can not be determined?

In the early stage of this study, we first discovered that gastric cancer lesions showed pink color change under MENBI (Fig. 1 and Figure S1), and named it as "pink pattern". Cancerous lesions are often accompanied by vascular changes. Abnormal blood vessels can also have reddish-brown color changes under the ME-NBI. Therefore, when the pink pattern appears in the cancerous area, it is easy to be confused with the color change of abnormal blood vessels in the same area, leading to the pink pattern is overlooked at the ME-NBI examination. So it's necessary to get rid of the vascular interference to recognize the pink pattern in the suspected lesions under ME-NBI. Later, the pathological diagnosis was performed on the suspected lesions that showed pink pattern under ME-NBI, it was found that the nucleus-to-plasma ratio of the gastric epithelial cells in cancerous area increased (Fig. 2 and Figure $\mathrm{S} 2)$. For this reason, we speculated that the pink pattern in the cancerous area under the ME-NBI may be related to 
the change of nucleus-to-plasma ratio in gastric epithelial cells of the same area. But the key point to link the pink pattern and the nucleus-to-plasma ratio of gastric epithelial cells was still unknown.

The NBI has two light bands with center wavelengths of 415nm (blue light) and 540nm (green light) [15]. The dualwavelength light band is confined to mucosa and does not penetrate the submucosal tissue [15], so the microstructure of the mucosal surface can be clearly visualized. Based on the above characteristics of the NBI light band, we tried to find the link point between the pink pattern and the nucleus-to-plasma ratio by analyzing the color features of crypt epithelium on the mucosal surface in NBI image and the epithelial cell layer in pathological image. In the pathological image, the nucleus looks dark while the cytoplasm is lighter under HE staining. The nucleus-toplasma ratio increases when the epithelial cells become cancerous, and the color of cancerous area become darker correspondingly under HE staining (Fig. 2 and Figure S2). Thus the change in nucleus-to-plasma ratio of epithelial cells can be represented by the color changes of these cells. If the color change trend of cancerous epithelial cells in the HE-stained pathological images is consistent with the color change trend of cancerous lesions in the ME-NBI images, it can be confirmed that the increased nucleus-to-plasma ratio of gastric cancer epithelial cells is highly correlated with the pink pattern of the cancerous lesions in the ME-NBI image. So the color change is considered as the key point to link the pink pattern and the nuclear-to-plasma ratio of cancerous epithelial cells.

In order to verify the pink pattern of the cancerous lesions in the ME-NBI images is highly correlated with the increase of nucleus-to-plasma ratio in gastric cancer epithelial cells, the color features of ME-NBI images(Fig. 3) and HEstained pathological images(Fig. 4) on gastric cancerous mucosal surface were extracted and quantized. Then the cosine similarity between the color values of the ME-NBI image and the HE-stained pathological image on gastric cancerous mucosal layer was calculated, and the results showed that the pink color change trend of the cancerous lesions in ME-NBI images was consistent with the color change trend of cancerous epithelial cells in HE-stained pathological images (Fig. 5, Table 3), suggesting that the pink pattern of ME-NBI image on the cancerous lesions is greatly related to the increased nucleus-to-plasma ratio of gastric cancer epithelial cells. Hence, the presence of a pink pattern is a warning sign that can be part of a preoperative assessment strategy for early gastric cancer in clinical practice.

Subsequently, the stored images captured by endoscope with NBI were evaluated independently by 12 endoscopists using VS classification system (test 1) and VS classification system plus pink pattern (test 2) respectively to assess the effect of performing ME-NBI after taking pink pattern into account. As far as overall diagnostic performance, the median AUC, accuracy and specificity of test 1 were $79.0 \%, 78.7 \%$ and $90.0 \%$ in all endoscopists, respectively, while the sensitivity was only $67.4 \%$, which was similar to that in previous studies $[5,10]$. However, when the "pink pattern" was taken into account for the ME-NBI diagnosis (test 2), the median values of AUC, accuracy, sensitivity and specificity increased to $87.3 \%, 87.0 \%, 78.4 \%$ and $95.0 \%$ (Table 4 and Fig. 7a), meaning that the cancer diagnostic capability of ME-NBI was significantly improved. Then these endoscopists were assigned to junior and experienced groups respectively according to the cases of endoscopy examinations ( $<10000$, junior; $\geq 10,000$, experienced). In the two subgroups, the AUC, accuracy, sensitivity and specificity of test 2 were significantly higher than those obtained from test 1(Fig. 7b and 7c). In addition, test 2 significantly improved the PPV and NPV compared with test 1 in all endoscopists, junior and experienced groups respectively (Table 4, Fig. 7). It has great significance in clinical practice for that the examination with high PPV and NPV can enable endoscopists to determine which lesion needs pathological diagnosis. These results have the potential to make so-called "optic biopsy" come true. Next, we calculated the Fleiss' kappa value of all endoscopists, junior and experienced groups in test 1 and test 2 to evaluate the agreement of the endoscopic diagnosis level among the participants. The interpretation of kappa value for all endoscopists, junior and experienced groups in test 1 and test 2 was at least moderate, especially the interpretation

Page $12 / 22$ 
of all endoscopists and experienced group was improved to substantial agreement in test 2(Table 5). The moderate or higher diagnostic agreement among participants is mainly due to the fact that the endoscopists all come from the same department and use similar diagnostic algorithm, which guarantees the consistency of test.

Table 5

Fleiss' kappa value of tests 1 and 2 in 12 endoscopists

\begin{tabular}{|lllll|}
\hline Endoscopists & Test 1 & & Test 2 & \\
\cline { 2 - 5 } & Fleiss' kappa & Agreement & Fleiss' kappa & Agreement \\
\hline All $(\mathrm{n}=12)$ & 0.51 & Moderate & 0.65 & Substantial \\
\hline Junior $(\mathrm{n}=6)$ & 0.47 & Moderate & 0.58 & Moderate \\
\hline Experienced $(\mathrm{n}=6)$ & 0.60 & Moderate & 0.76 & Substantial \\
\hline
\end{tabular}

Fleiss' kappa values were evaluated by $\mathrm{R}$ with IpSo/ve and irr packages. Kappa values of 0.01 to $0.20,0.21$ to 0.40 , 0.41 to $0.60,0.61$ to 0.80 , and 0.81 to 1.00 were defined as slight agreement, fair agreement, moderate agreement, substantial agreement, and almost perfect agreement, respectively.

At the same time, from the results of this study, we devised a provisional strategy for differentiated EGC diagnosis under ME-NBI by taking the pink pattern as a supplement to the VS classification system (Fig. 8). Briefly, gastric endoscopic examination is taken by using conventional white-light imaging (C-WIL) firstly. When a suspicious lesion is detected, the endoscope should be switched to ME-NBI to differentiate cancer and non-cancer. The key step to diagnose gastric cancer and non-cancer is to determine the DL between the suspicious lesion and the background mucosa. If a DL is absent, it's easy to diagnose the suspicious lesion as noncancerous. If a DL is indeterminate, the pink pattern can be taken into account and diagnosis of a cancerous lesion can probably be made. If a DL is clearly visible, the subsequent presence of an IMVP and IMSP should be determined. If IMVP and/or IMSP are identified within the DL, the suspicious lesion can be diagnosed as gastric cancer; if IMVP and/or IMSP are absent, the lesion can be determined as noncancerous. But if IMVP and/or IMSP are indeterminate within the DL, the pink pattern is also helpful to diagnose EGC. By the way, our study has some limitations. First, this study was retrospective and did not involve real-time assessment, the endoscopic diagnosis was just performed by using stored images. The selection bias might occur when the stored images were selected for the two diagnostic tests. Second, we recruited the 12 endoscopists only from one institution to perform diagnostic tests, which might easily lead to the participant bias. Third, the number of lesions and endoscopists in our study was small, and this could result in insufficient power in evaluating diagnostic performance. To overcome these limitations, in future study, we will conduct on-site real-time evaluation of newly detected and undiagnosed gastric lesions. Furthermore, larger number of cases and endoscopists from multiple centers are required in future study to evaluate the diagnostic performance of pink pattern for EGC.

\section{Conclusions}

We discovered that gastric cancerous lesions showed pink color change under ME-NBI, and named it as "pink pattern". Then the high correlation between the "pink pattern" of ME-NBI images and the nucleus-to-plasma ratio change of gastric epithelial cells was identified in this study. Finally, the results of our study demonstrated that the pink pattern as detected under ME-NBI is an extremely useful marker for the diagnosis of the differentiated EGC. 
Meanwhile, we also proposed a provisional strategy for differentiated EGC diagnosis under ME-NBI by taking the pink pattern as a supplement to the VS classification system.

\section{Abbreviations}

ME-NBI: magnifying endoscopy with narrow-band imaging; EGC: early gastric cancer; AUC: area under curve; PPV: positive predictive value; NPV: negative predictive value; VS: vessel-plus-surface; DL: demarcation line; IMVP : irregular microvascular pattern; IMSP: irregular microsurface pattern; ESD: Endoscopic submucosal dissection; CWIL: white-light imaging

\section{Declarations}

\section{Ethics approval and consent to participate}

This study is retrospective and performed by using stored images. The study protocol was approved by the Ethics Committee of the Zhejiang Cancer Hospital.

\section{Consent for publication}

Not applicable

\section{Availability of data and materials}

The datasets used and/or analysed during the current study are available from the corresponding author on reasonable request.

\section{Competing interests}

The authors declare that they have no competing interests.

\section{Funding}

None.

\section{Authors' contributions}

SW and SSC designed the study. JPY, RWR and YDL contributed to the data collection. CS, JYJ, MC and CHJ did the images processing and cosine similarity calculation. YLT and ZC did the data analysis, under supervision of SW and SSC. SSC, JPY and RWR drafted the paper and interpreted the results. SW revised the manuscript.

\section{Acknowledgements}

We thank Hithink RoyalFlush Information Network Company for providing computer image processing technique to help us process the images.

\section{References}


1. Sung H, Ferlay J, Siegel RL, Laversanne M, Soerjomataram I, Jemal A, et al. Global cancer statistics 2020: GLOBOCAN estimates of incidence and mortality worldwide for 36 cancers in 185 countries. Cancer J Clin. 2021;0:1-41. https://doi.org/10.3322/caac.21660.

2. Kaltenbach T, Sano Y, Friedland S, Soetikno R. American Gastroenterological Association (AGA) Institute technology assessment on image-enhanced endoscopy. GASTROENTEROLOGY. 2008;134(1):327-40. https://doi.org/10.1053/j.gastro.2007.10.062.

3. Muto M, Katada C, Sano Y, Yoshida S. Narrow band imaging: a new diagnostic approach to visualize angiogenesis in superficial neoplasia. Clin Gastroenterol Hepatol. 2005;3(7 Suppl 1):16-20. https://doi.org/10.1016/s1542-3565(05)00262-4.

4. Yao K, Anagnostopoulos GK, Ragunath K. Magnifying endoscopy for diagnosing and delineating early gastric cancer. ENDOSCOPY. 2009;41(5):462.

5. Ezoe Y, Muto M, Uedo N, Doyama H, Yao K, Oda I, et al. Magnifying Narrowband Imaging Is More Accurate Than Conventional White-Light Imaging in Diagnosis of Gastric Mucosal Cancer. GASTROENTEROLOGY. 2011;141(6):2017-25. https://doi.org/10.1053/j.gastro.2011.08.007.

6. Uedo N, Ishihara R, lishi H, Yamamoto S, Yamada T, Imanaka K, et al. A new method of diagnosing gastric intestinal metaplasia: narrow-band imaging with magnifying endoscopy. ENDOSCOPY. 2006;38(8):819.

7. Yao K, Oishi T, Matsui T, Yao T, Iwashita A. Novel magnified endoscopic findings of microvascular architecture in intramucosal gastric cancer. GASTROINTEST ENDOSC. 2002;56(2):279-84. https://doi.org/10.1016/s00165107(02)70194-6.

8. Muto M, Yao K, Kaise M, Kato M, Uedo N, Yagi K, et al. Magnifying endoscopy simple diagnostic algorithm for early gastric cancer (MESDA-G). DIGEST ENDOSC. 2016;28(4):379-93. https://doi.org/10.1111/den.12638.

9. Doyama H, Nakanishi H, Yao K. Image-Enhanced Endoscopy and Its Corresponding Histopathology in the Stomach. GUT LIVER. 2020. https://doi.org/10.5009/gnl19392.

10. Yao K, Doyama H, Gotoda T, Ishikawa H, Nagahama T, Yokoi C, et al. Diagnostic performance and limitations of magnifying narrow-band imaging in screening endoscopy of early gastric cancer: a prospective multicenter feasibility study. GASTRIC CANCER. 2014;17(4):669-79. https://doi.org/10.1007/s10120-013-0332-0.

11. Schlemper RJ, Riddell RH, Kato Y, Borchard F, Cooper HS, Dawsey SM, et al. The Vienna classification of gastrointestinal epithelial neoplasia. GUT. 2000;47(2):251-5. https://doi.org/10.1136/gut.47.2.251.

12. Novotný V. Implementation Notes for the Soft Cosine Measure. In: 2018-01-01 2018: ACM; 2018: 1639-1642.

13. Sidorov G, Gelbukh A, Gómez-Adorno H, Pinto D. Soft Similarity and Soft Cosine Measure: Similarity of Features in Vector Space Model. Computación y Sistemas. 2014;18(3).https://doi.org/10.13053/cys-18-3-2043.

14. Ikehara H, Doyama H, Nakanishi H, Hatta W, Gotoda T, Ishikawa H, et al. Analysis of factors related to poor outcome after e-learning training in endoscopic diagnosis of early gastric cancer using magnifying narrow-band imaging. GASTROINTEST ENDOSC. 2019;90(3):440-7. https://doi.org/10.1016/j.gie.2019.04.230.

15. Yao K, Takaki Y, Matsui T, Iwashita A, Anagnostopoulos GK, Kaye P, et al. Clinical Application of Magnification Endoscopy and Narrow-Band Imaging in the Upper Gastrointestinal Tract: New Imaging Techniques for Detecting and Characterizing Gastrointestinal Neoplasia. Gastrointest Endosc Clin N Am. 2008;18(3):415-33. https://doi.org/10.1016/j.giec.2008.05.011.

\section{Figures}



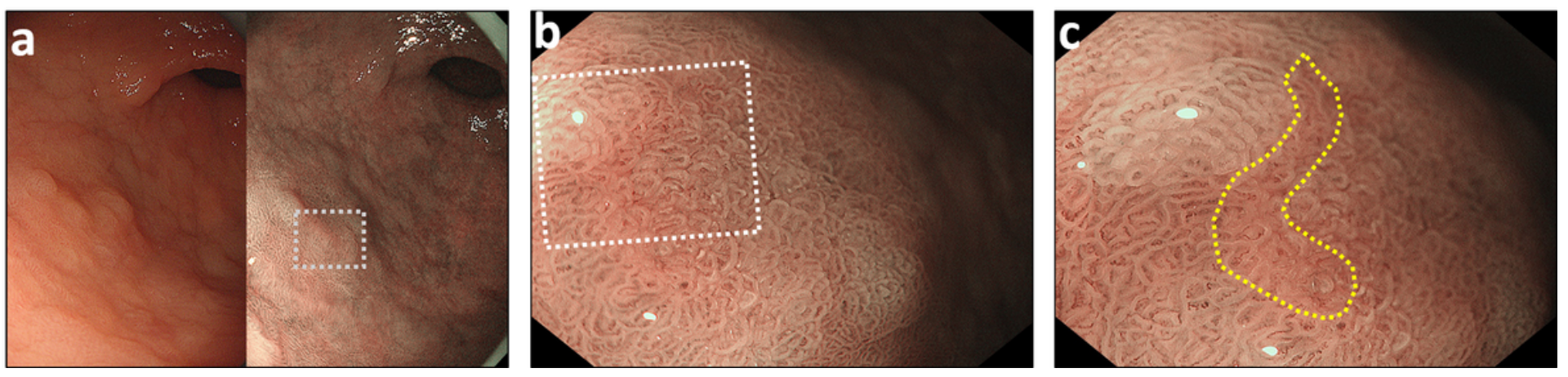

Figure 1

Representative case of "pink pattern" when the demarcation line (DL) is indeterminate. (a) The suspected lesion of early cancer in the gastric antrum (the dotted box area). Left is conventional white light imaging findings and right is narrow band imaging findings. (b) Magnified image of the dotted box area in part (a). The DL is indeterminate. (c) Magnified image of the dotted box area in part (b). The "pink pattern" is observed in the lesion (within the yellow dotted line)
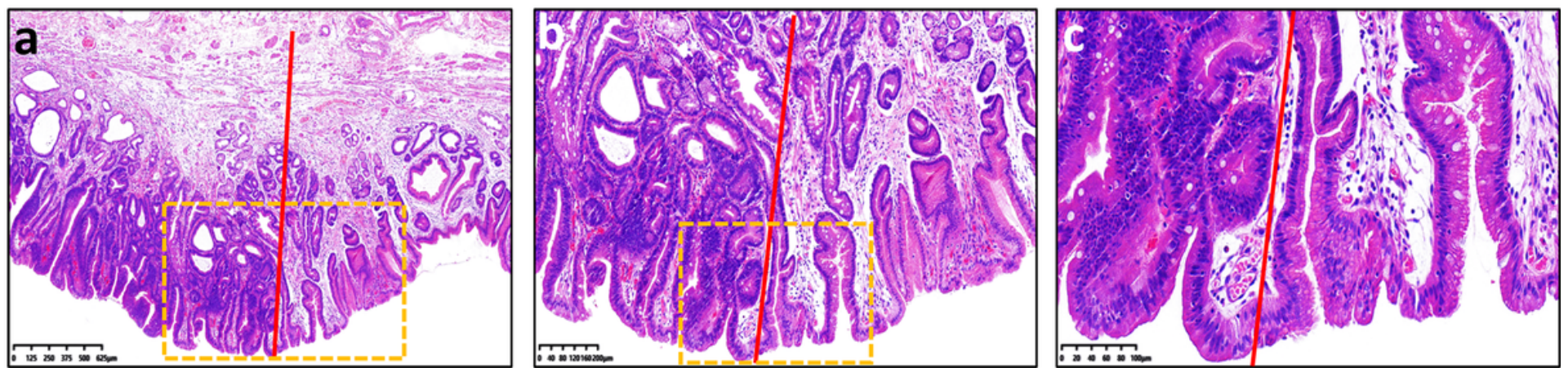

\section{Figure 2}

Histopathological findings of Fig. 1 under different magnification. (a-c) Hematoxylin and eosin staining of the resected specimen revealed that the histopathological diagnosis was gastric cancer. The color of gastric epithelial cells at the left of red line looks much darker than that at the right of red line. (b) Magnified image of the dotted box area in part (a). (c) Magnified image of the dotted box area in part (b). The nucleus-to-plasma ratio of epithelial cells at the left of red line is increased compared with that at the right of red line. 


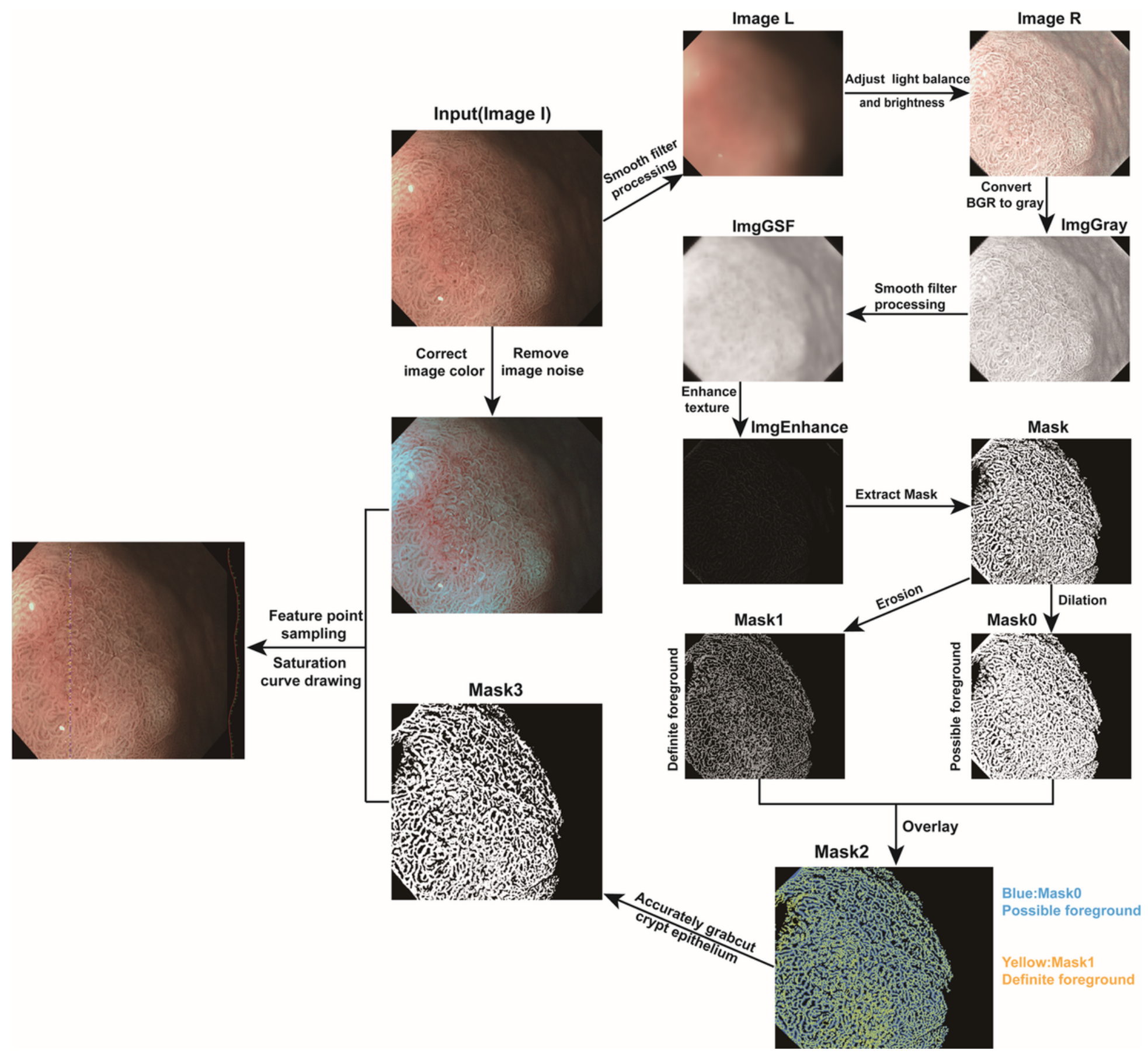

Figure 3

Endoscopic image processing and color features extraction by python. 

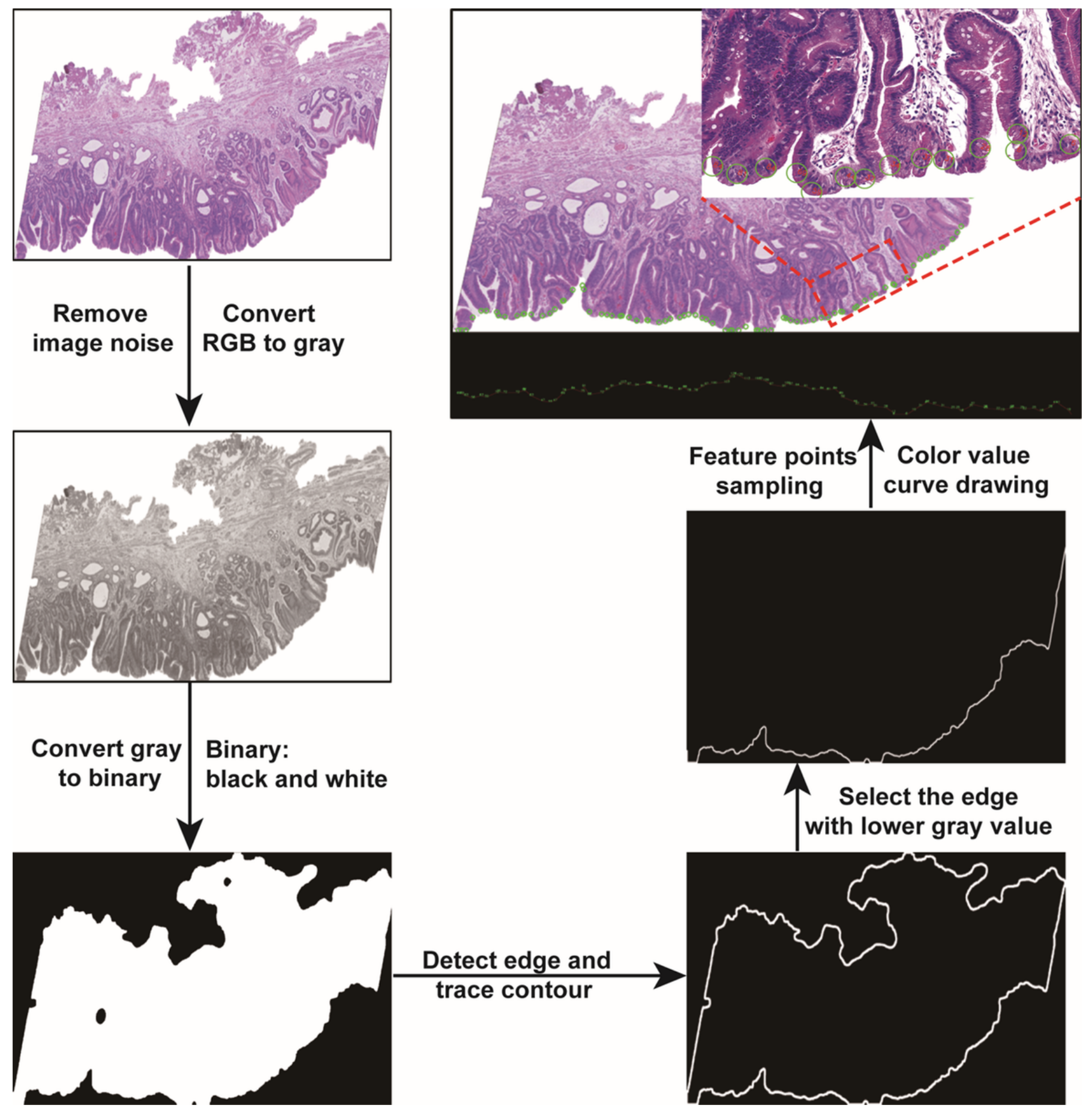

Figure 4

Pathological image processing and color features extraction by python. 
a

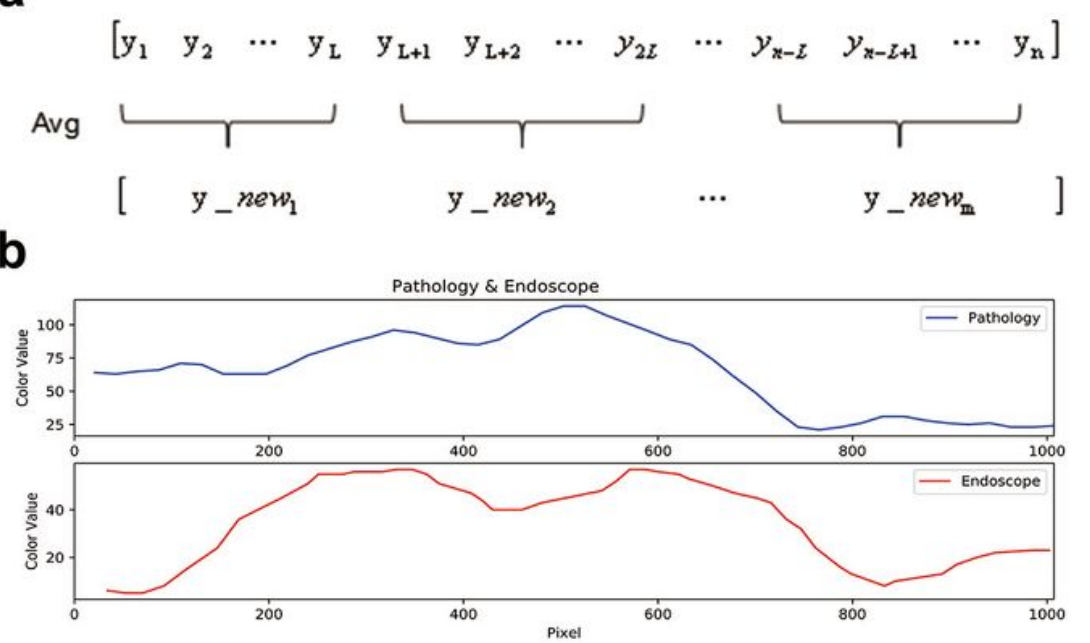

C

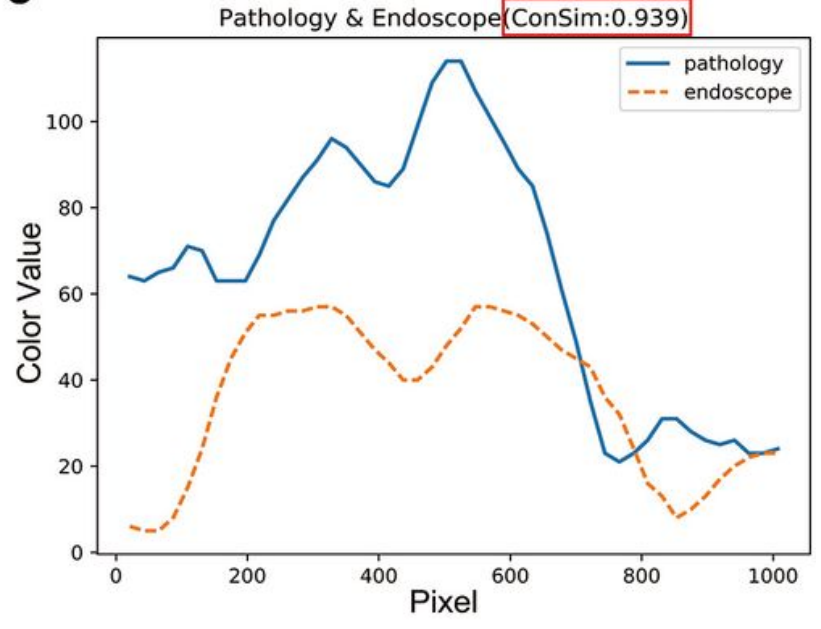

\section{Figure 5}

Similarity evaluation for the color curves trend between endoscopic image and pathological image. The color values list of pathological image was averagely sampled $(A)$ to make it consistent with the length of the color values list of the endoscopic image (B). (C) The cosine value and the color curves of endoscopic and pathological image are summarized in one figure. 


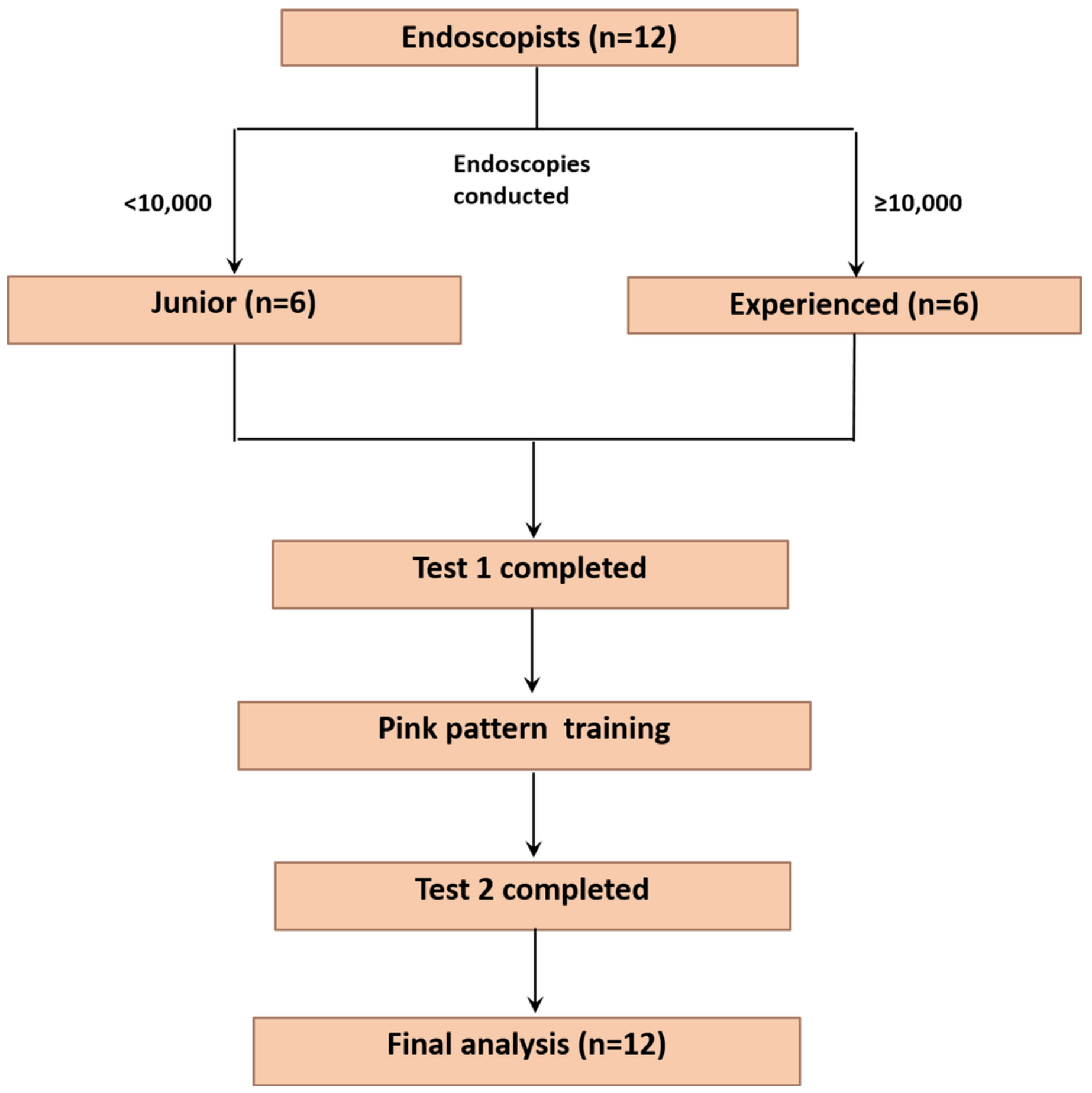

Figure 6

The flowchart of diagnostic test. 


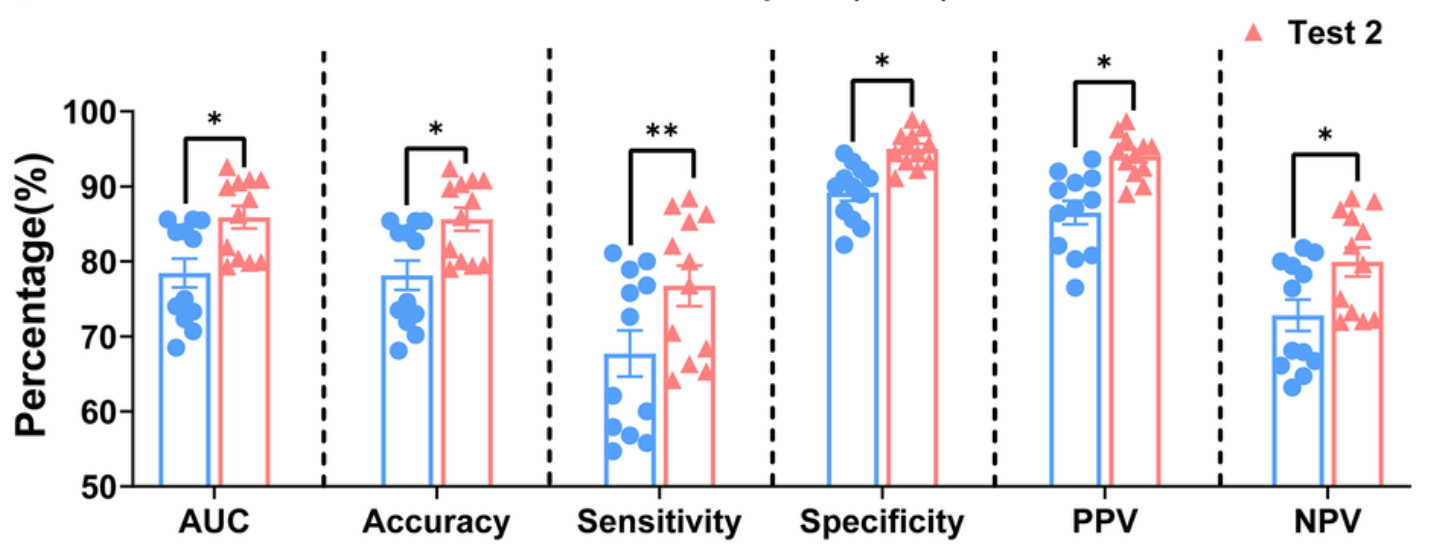

b

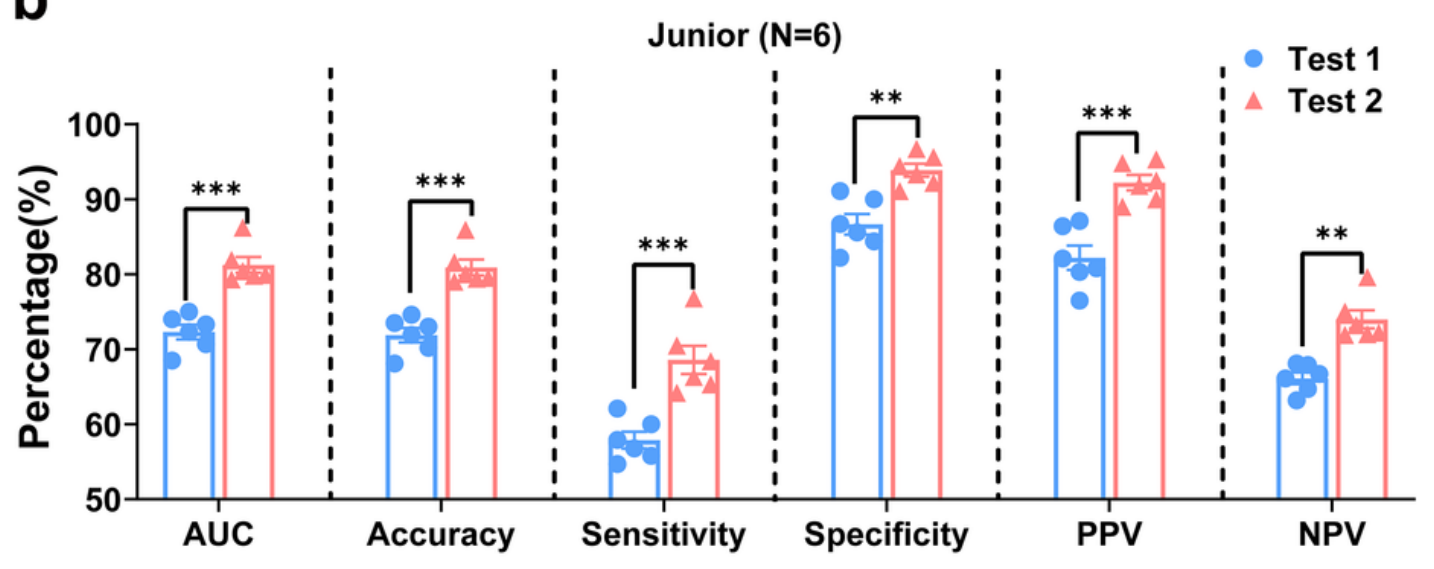

C

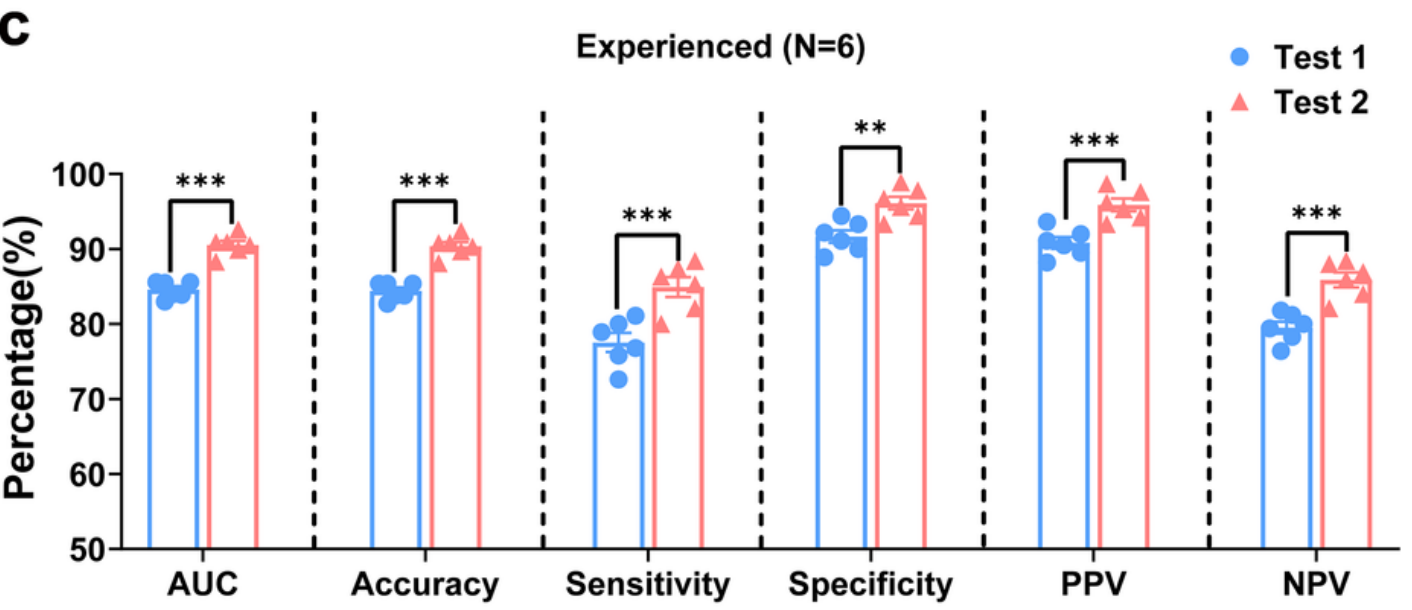

Figure 7

Diagnostic performance comparison between tests 1 and 2 in all endoscopists (a), junior (b) and experienced (c) groups. AUC, area under curve; PPV, positive predictive value; NPV, negative predictive value. P values were calculated by using Mann-Whitney test. ${ }^{\star} P<0.05,{ }^{\star \star} P<0.01$, and ${ }^{\star \star *} P<0.001$. 


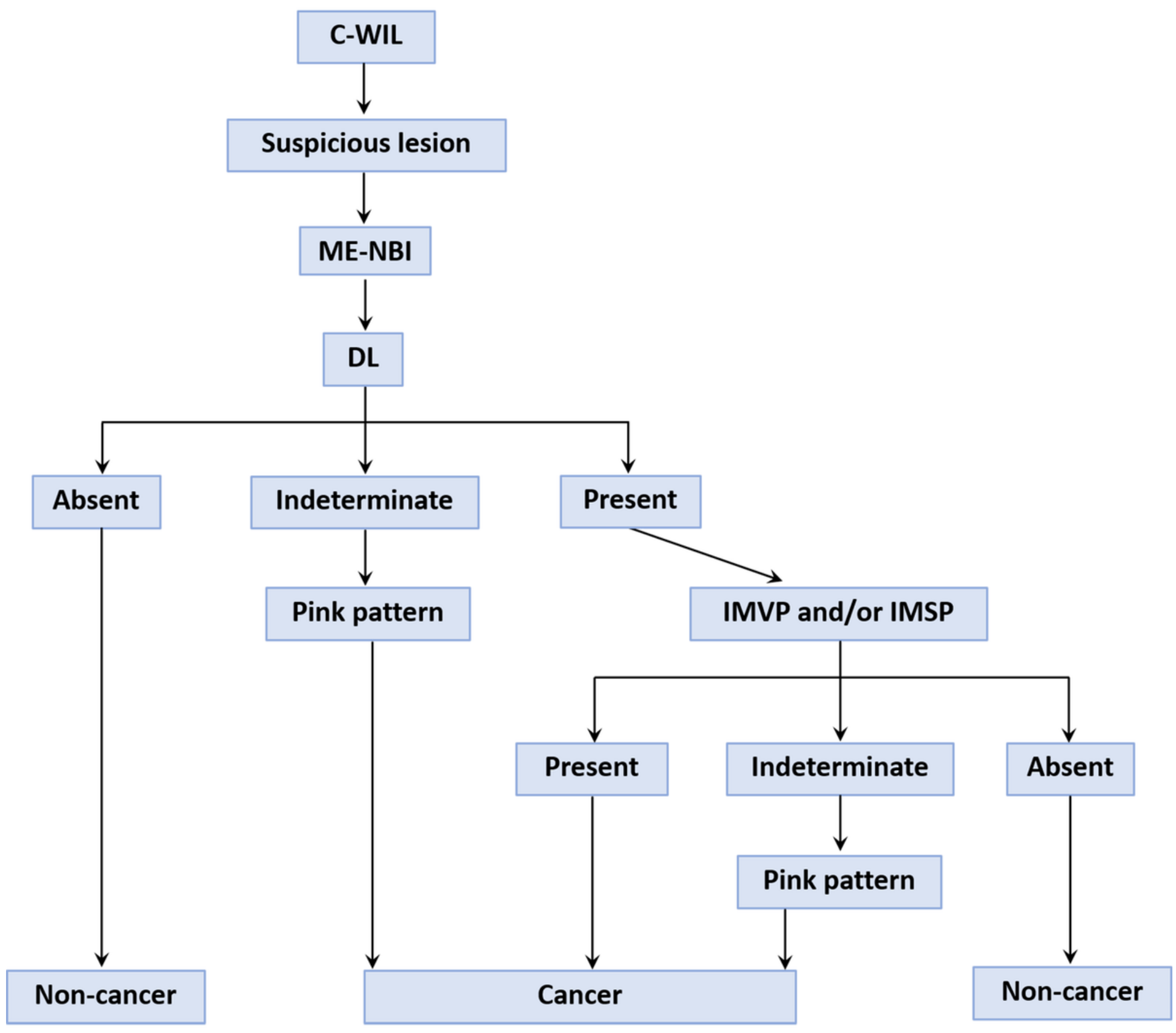

Figure 8

A provisional strategy for gastric cancer diagnosis by taking "pink pattern" as a supplement to VS classification system. C-WIL, conventional white-light imaging; ME-NBI, magnifying endoscopy with narrow-band imaging; $D L$, demarcation line; IMVP, irregular microvascular pattern; IMSP, irregular microsurface pattern.

\section{Supplementary Files}

This is a list of supplementary files associated with this preprint. Click to download.

- Supplementarymaterials.pdf 